Archives de sciences sociales des religions

149 | janvier-mars 2010

Varia

\title{
Mon compagnonnage avec Doris Bensimon
}

Yves Chevalier

\section{(2penEdition}

Journals

Édition électronique

URL : http://journals.openedition.org/assr/21998

DOI : $10.4000 /$ assr. 21998

ISSN : $1777-5825$

Éditeur

Éditions de l'EHESS

Édition imprimée

Date de publication : 31 mars 2010

Pagination : 287-289

ISBN : 978-2-7132-2253-5

ISSN : 0335-5985

Référence électronique

Yves Chevalier, " Mon compagnonnage avec Doris Bensimon ", Archives de sciences sociales des religions [En ligne], 149 | janvier-mars 2010, mis en ligne le 01 juin 2010, consulté le 21 septembre 2020. URL : http://journals.openedition.org/assr/21998; DOI : https://doi.org/10.4000/assr.21998

() Archives de sciences sociales des religions 


\section{Yves Chevalier}

\section{Mon compagnonnage avec Doris Bensimon}

C'est en 1970 que j'ai rencontré, pour la première fois, Doris Bensimon. Je venais de terminer une maîtrise de sociologie sur l'histoire et la sociodémographie de l'immigration des juifs en Palestine puis en Israël depuis la fin du XIX siècle. Je cherchais un directeur de thèse pour poursuivre ce travail ; mais à Paris $\mathrm{V}$, où j'étais inscrit et où j'enseignais déjà comme chargé de cours, personne ne travaillait sur ce sujet. C'est Georges Friedmann, que j'avais contacté, qui m'adressa à Madame Bensimon - qui, au CNRS, au sein du Groupe de Sociologie des Religions, était en charge de l'équipe travaillant sur la sociologie du «Judaïsme " au sens large. Elle accepta de suivre mon travail (même s'il ne lui était pas possible, à l'époque, de m'inscrire sous sa direction), et c'est comme cela que commença, pour moi, une collaboration enrichissante.

Ma thèse de $3^{\mathrm{e}}$ cycle, sur "La stratification sociale de la société israélienne ", soutenue en février 1973, Madame Bensimon m'ouvrit en effet plusieurs opportunités. D'une part en m'acceptant en tant que vacataire au sein de son équipe du CNRS, où elle me fit participer aux recherches qu'elle menait alors sur la socio-démographie des juifs de France ; ensuite, en me recommandant auprès du Directeur du département d'hébreu de l'Institut national des langues et civilisations orientales (INALCO), le Grand Rabbin Sirat, pour assurer un cours de "Sociologie d'Israël » dans le cursus de la licence d'hébreu, cours que j'ai assuré de 1976 à 1991.

Au CNRS, j'ai d'abord participé au codage du « Recensement de la population juive de Paris de 1872 » (dont une copie des registres avait été conservée aux Archives du Consistoire de Paris). Avec Françoise Fougeroux, alors collaboratrice technique, Régine Azria et Martine Cohen, vacataires, nous avons travaillé, rue d'Athènes, dans la pièce du fond de cet appartement où était logé de Centre de Sociologie des Religions (annexe du Centre de Sociologie de la rue Cardinet), à la mise au point du code numérique permettant de traduire les mentions des registres en cartes perforées - et, partiellement, si mes souvenirs sont exacts, au codage lui-même. Avec d'autres sources, les résultats informatisés de ce recensement ont servi à Doris Bensimon pour rédiger puis publier, en 1976, 
aux Presses orientalistes de France (éditions de l'INALCO), son livre Sociodémographie des Juifs de France et d'Algérie ${ }^{1}$.

Mais c'est surtout à l'étude, par questionnaires, de la population juive de France dans les années 1970-1980, qui a abouti à l'ouvrage que Doris Bensimon a signé avec Sergion Della Pergola ${ }^{2}$, que j’ai participé, chargé de la réalisation du tirage, particulièrement complexe, de l'échantillon à partir des listes électorales des communes retenues - puisque nous cherchions à interroger les personnes se considérant et se déclarant comme juives dans un échantillon représentatif de la population française (cet échantillon a été présenté lors d'un Colloque que Doris Bensimon a organisé à Paris, en $1978^{3}$ ). Lorsque les mairies des communes retenues étaient informatisées (ce qui n'était pas encore général à l'époque), il s'agissait de négocier avec le responsable du service le tirage, selon un taux de sondage déterminé, d'un listing comportant les noms et les adresses d'habitants de la commune. Mais lorsqu'elles n'étaient pas informatisées, la seule solution était le relevé manuel d'un nom tous les noms du registre : ce qui a été fait des heures durant pour la seconde phase de l'enquête de Paris - ou, comme à Nice, après le micro-filmage sur place des registres, afin de pouvoir disposer rue d'Athènes d'une copie de la liste à traiter. Une fois l'échantillon établi, avec Françoise Fougeroux, ont été organisées les opérations d'envoi et de suivi des questionnaires par le pointage géographique des répondants. On sait que cette grande enquête, volet français d'une recherche internationale coordonnée par l'Institut du Judaïsme contemporain de l'Université hébraïque de Jérusalem, est venue confirmer que, par suite de l'évolution démographique et migratoire, la population juive de France était bien, numériquement, la plus importante d'Europe occidentale, après celles des États-Unis, d'Israël et d'URSS.

Je connaissais le parcours de Doris Bensimon, telle qu'elle le retrace dans son autobiographie ${ }^{4}$, bien que nous n'en ayons jamais parlé ensemble ; au début de ma collaboration avec elle, une amie commune, qui l'avait côtoyée au moment de la guerre et juste après, m'avait raconté ses souvenirs. Mais notre collaboration se plaçait sur un autre plan et ce dont je lui suis profondément redevable, c'est de m'avoir associé à ses recherches et de m'avoir permis, à un moment

1. Doris Bensimon-Donath, Socio-démographie des juifs de France et d'Algérie, POF-Études, 1976, $376 \mathrm{p}$.

2. Doris Bensimon, Sergio Della Pergola, La population juive de France: Socio-démographie et identité, Paris, Jérusalem, CNRS, The Institut of Contemporary Jewry-The Hebrew University of Jerusalem, 1984, $436 \mathrm{p}$.

3. Communautés juives (1880-1978) Sources et méthodes de recherche, Actes du Colloque international organisé à Paris par l'Institut national des Langues et Civilisations orientales et le Centre inter-universitaire des Hautes études du Judaïsme contemporain, 13-15 février 1978, Clichy, décembre 1979, 475 p. (Cf. pp. 248-257).

4. Doris Bensimon-Donath, Quotidien du vingtième siècle. Histoire d'une vie mouvementée, L'Harmattan, coll. "Graveurs de mémoire ", 2007, 234 p. 
difficile de ma propre carrière, d'être - même si cela a été d'une manière provisoire et quelque peu marginale - intégré dans une équipe. Mon départ pour la province (à l'Université de Tours en 1988) n'a pas rompu nos échanges, même s'ils se sont alors situés sur un plan plus personnel. Je pense qu'elle m'estimait ; en ce qui me concerne, je garde le souvenir de quelqu'un qui m'a beaucoup et généreusement appris. Que ce court témoignage soit l'expression de mon sincère et chaleureux "merci ».

Yves CHEVALIER

Ancien professeur de Sociologie à l'Université de Tours, ancien doyen de l'UFR Arts et Sciences humaines 